\title{
Aging Workers: Work Environment as a Factor in Employee Mental Health
}

\author{
Wendy A. Coduti, ${ }^{1}$ Kristin Tugman, ${ }^{2}$ Susanne M. Bruyère, ${ }^{3}$ and Valerie Malzer ${ }^{4}$ \\ ${ }^{1}$ The Pennsylvania State University, United States of America, \\ 2 Prudential, United States of America, \\ ${ }^{3}$ Cornell University, United States of America \\ ${ }^{4}$ Cornell University, United States of America
}

\begin{abstract}
In 2014, the health and productivity team of the disability insurance provider, Unum, conducted a mixed methods study that included qualitative interviews with internal mental health disability claims professionals, and external interviews with employers. Quantitative data of 15 employers were analysed to identify descriptive statistics involving mental health short-term disability (STD) claims. Workplace factors were examined to understand best practices among companies, related to mental health STD, to identify work environments that may increase or decrease mental health disabilities. Quantitative data found workers aged 40 to 49 had the highest rates of mental health STD claims and workers aged 50 to 59 had the longest duration of absence. Anxiety and depression were the main reasons for mental health absences from work. Results from the qualitative interviews showed a supportive work culture (i.e., work-life balance, good benefits, successful wellness programs) may lead to higher STD claim rates, demonstrating workers in these environments may feel more comfortable disclosing and seeking help for mental health disabilities. Conclusions from this study indicate that although presenteeism rates for mental health are high and impact employers financially, having higher STD claim rates may be more cost effective than having employees with mental health conditions remain at work instead of filing STD claims, seeking treatment and returning to productive employment. Employee age can impact rate and duration of mental health STD claims, meaning employers should implement workplace practices that support overall mental health of employees.
\end{abstract}

Keywords: aging workers, mental health, workplace culture, disability

As the workforce ages, rates of disability also increase. It is well documented that chronic conditions increase with age and with that many comorbid mental health conditions (Keyes, 2005). Employees are choosing to remain employed longer and aging workers are one of the fastest growing groups in the workforce today (Bjelland et al., 2010; Toossi, 2007). Estimates from the United States (US) Bureau of Labor Statistics report that between 2006 and 2016 workers aged 55 and older will increase by $47 \%$ (Toossi, 2007). The increased demographic of aging workers will make managing disability in the workplace imperative for employers.

A 2010 study using US Equal Employment Opportunity Commission Integrated Mission Systems data (Bjelland et al., 2010) found employment discrimination claims filed by older workers (over the age of 40) were focused on issues related to reasonable accommodations, retaliation, and termination. Moss, Ullman, Starrett, Burris, and Johnsen (1999) reported that under the Americans with Disabilities Act of 1990, the most recurrent health condition cited in employment discrimination charges were for mental health. With the increase in workers remaining in the workplace longer and the increase in discrimination claims filed by older workers around disability issues, employers will need to seek a better understanding of the impact of disability, specifically areas around mental health.

\section{Prevalence of Mental Health}

Mental health prevalence rates range between $12 \%$ and $26 \%$ of the population in North America alone in a

Address for correspondence: Wendy A. Coduti, PhD, CRC, The Pennsylvania State University, 311 Cedar Building, University Park, PA 16802, United States of America. E-mail: wac16@psu.edu

Author Note: Kristin Tugman was a member of the Unum health and productivity team at the time this study was conducted. 
given year (Dewa \& McDaid, 2011). Depression is now one of the most prevalent disorders in the workplace (Gallie, Schultz, \& Winter, 2011; Gnam, 2005). A 2013 study conducted by Ferrari and colleagues found depression to be the second leading cause of disability globally; and that by 2030 , depression will be the number one cause of lost productivity (Cuijipers, Beekman \& Reynolds, 2012). About half of all Americans will meet the criteria for a mental health disorder at some point in their lifetime (Kessler et al., 2005); globally depression accounts for one-third of all mental health occurrences (Alwan, 2011).

Mental health conditions overall are one of the leading causes of absenteeism (World Health Organization, 2005) and while $80 \%$ of US employers offer coverage for mental health benefits (Society for Human Resource Management, 2009), employers often fail to realise how the work environment contributes to poor mental health in their employees. Organisational factors (e.g., employee involvement, supportive culture, interpersonal relationships in the workplace) have been shown to impact employee mental health (Kelloway \& Day, 2005). Among a meta-analysis of 500 studies, Faragher, Cass, and Cooper (2005) reported a strong correlation between mental health status and job satisfaction. Since there is a higher incidence rate of mental disorders in the working population among those aged 40 to 45 (Godin et al., 2009), employers will need to consider how their workplaces impact the mental health of its aging workers.

\section{Mental Health Impact on Employers}

The impact of reduced productivity can be very costly for employers. Overall absenteeism costs associated with mental health are about $7 \%$ of total payroll; and mental health conditions are a leading cause of absence (Watson Wyatt Worldwide, 2000). Presenteeism, or inability to work at full capacity, costs the US nearly US $\$ 150$ billion per year (HR Specialist: Compensation \& Benefits, 2013) and presenteeism in individuals with depression costs approximately US $\$ 36$ billion (Stewart, Ricci, Chee, Hahn, \& Morganstein, 2003). However, Stewart and colleagues (2003) also reported that costs associated with lost productivity and absenteeism due to depression is approximately US $\$ 8.3$ billion, which means lost productivity costs are higher for individuals with depression while they are at work (presenteeism) versus absent from work (absenteeism). Juniper (2012) reports presenteeism can also be caused by workplace stress that includes, in part, a lack of work-life balance, high workload, and conflict with coworkers.

Mental health disorders are the fastest growing shortterm disability claims for employers (Dewa, Lin, Kooehoorn, \& Goldner, 2007). In a survey, 53\% of employers stated return to work for employees with a mental health condition was more difficult than a physical impairment
(Watson Wyatt Worldwide, 1998), yet research shows that with early intervention and treatment, costs associated with mental health can be reduced significantly (McCulloch et al., 2001). In fact, Claxton, Chawla, and Kennedy (1999) found that for employees with depression, absenteeism increased during the six months prior to diagnosis but then decreased after the start of drug treatment in each of the subsequent six months.

The most common type of accommodation request for individuals with a mental health issue is a leave of absence (Center, 2011). In a 2007 article, Briand, Durand, St-Arnaud, and Corbière report return-to-work studies are limited in relation to mental health. St-Arnaud, St Jean, and Damasse (as cited in Briand et al., 2007) state that for employees who are absent from work due to mental health issues, the work environment is named in $90 \%$ of cases as a reason for not remaining or returning to work. It is clear that the work environment not only acts as a potential source of mental health issues, but also can inhibit employee access to employment. Dewa and McDaid (2011) state there is an 'economic argument for investing in the mental health of workers' and 'mental disorders do affect productivity and that they have a number of effects, including decreased labor force participation, increased unemployment, and decreased ability to work' (p. 45).

\section{Work Environment}

Creating a workplace that supports disability, such as return-to-work and disability management programs, promotes a supportive culture for employees, especially those with disabilities. Employees' mental health, particularly anxiety and depression (Arnetz, Lucas, \& Arnetz, 2011; Martin, Karanika-Murray, Biron, \& Sanderson, 2014) has been shown to be impacted by an organisation's culture (Bronkhorst, Tummers, Steijn, \& Vijverberg, 2014; Kelloway, \& Day, 2005). A review of data from the US Equal Employment Opportunity Commission (USEEOC), the agency that enforces the employment provisions of the Americans with Disabilities Act of 1990, reveals that almost 13\% of individuals filing employment disability discrimination charges between 2005 and 2010 were individuals reporting mental health disabilities (depression, anxiety disorder, and bipolar disorder), and these claims are increasing over time (von Schrader, 2011). In addition, 15\% of charges filed during this same time period across all disabilities were filed on the issue of harassment, and charges for the basis of retaliation increased from $13 \%$ to $23 \%$ (von Schrader, 2011). This suggests that businesses across America may very well have workplace culture issues that would make disability disclosure difficult for a person with a mental health disability, as well as other disabilities, and possibly thereby further impact the individual's overarching ability to enjoy and fully contribute to their work environment. Supportive employment environments, 
including those inclusive of disability, have been shown to positively impact job satisfaction, employee commitment and productivity (Disability Case Study Research Consortium, 2008).

Perceptions of the climate within an organisation around disability inclusion are very important because they influence how individuals with disabilities report experiencing their environment, including 'their felt embeddedness within the organisation, perceived organisational support, perceptions of the quality of the relationship with their immediate supervisor, fit between their abilities and the demands of the job, commitment to the organisation, experiences with disability-related bias, and willingness to disclose their disability to others' (Nishii \& Bruyère, 2014, pp. 6-7). Organisations with less help for employees have also been associated with higher mental health distress (Ericksen, Tambs, \& Knardahl, 2006).

One part of an individual's management of disability in the workplace includes the decision to disclose (or not) a disability to an employer. Organisations are increasingly interested in facilitating disclosure, as some, such as federal subcontractors, have requirements to accurately record the proportion of employees in their workplace who have a disability. Their ability to do so is dependent in large measure on the comfort level of individuals in disclosing their disability. Disability disclosure is one important element for consideration in assessing whether the workplace climate is inclusive of people with disabilities. Individuals opt to disclose disabilities to their employers for a wide range of reasons - from needing a workplace accommodation to having a desire to share their 'whole selves'. The decision to disclose a nonevident disability to an employer can be complex (Dalgin \& Gilbride, 2003). As Baldwin and Marcus (2011) state 'persons with mental health disorders experience stigma comparable to persons with AIDS or ex-convicts' (p. 54). Common concerns of disclosure include lowered expectations, lack of respect, isolation from workers, decrease in job responsibility, and being passed over for promotion (Dalgin \& Bellini, 2008; Dalgin \& Gilbride, 2003; Madaus, 2008; von Schrader, Malzer, Erickson \& Bruyère, 2011).

The decision to disclose a disability is a very personal one. There are very real concerns for individuals about disclosure, which may include the belief that disclosing a disability could lessen the likelihood of being selected for a position, or if already employed, fear that such a disclosure might diminish the likelihood of future career advancement opportunities. Also of concern, and not an unfounded fear, is being treated or viewed differently subsequent to disclosure, with a supervisor and coworkers altering their perceptions of the competency of the individual. Reasons for individuals to consider disclosure, even in the face of these concerns, are the need for an accommodation to effectively meet workplace performance expectations.
There are also ways to proactively address the potential barriers in the workplace. One critical element is raising the awareness of supervisors to act positively towards disclosing employees, and reinforcing the critical role supervisors play in creating a climate of inclusion for individuals with disabilities. Other proactive behaviours include encouraging supportive supervisoremployee relationships, providing a disability-friendly workplace as well as actively monitoring the organisation in which to reinforce disability-positive messaging, recruiting individuals with disabilities, and establishing observable success of employees after disclosure of a disability (von Schrader et al., 2011). Employees are significantly (at least 1.5 times) more likely to selfdisclose to other individuals than to formal organisational structures, such as human resource (HR) departments, Equal Employment Opportunity representatives, or in confidential employee records. When employees with disabilities work within departments in which all employees feel supported and fairly treated, they are more likely to feel that disclosing their disability is 'safe' (Nishii \& Bruyère, 2014). As a result of disclosure, an individual may also find that their supervisor and work peers are surprisingly supportive and appreciate such candour, which helps others in the workplace to have a better understanding of an individual's behaviour that was previously perplexing (MacDonald-Wilson, 2005).

Workplace policies and practices that contribute to a positive climate for inclusion for individuals with disabilities include the extent to which managers have undergone disability awareness training, the awareness of department managers of disability policies and practices, and the perceptions of department managers that disability policies adopted have been done so by the organisation for 'right reasons'. It is critical that managers feel that the company's disability inclusion policies are driven by a genuine concern about inclusion and not just to comply with related regulations or to mimic the practices of their competitors (Nishii \& Bruyère, 2014).

For this current study, there were three research questions: (1) practices of employers with a small number of STD mental health claims; (2) how does workplace culture contribute to mental health claims; and (3) what are the characteristics of employees on STD for mental health claims (using descriptive statistics of a cross-section of companies with varying levels of mental health STD claims).

\section{Method}

\section{Overview}

This article will discuss the results of a 2014 study conducted by the health and productivity team at Unum (a disability insurance provider), in an effort to understand best practices among companies that experience a small number of mental health disability claims (below the mean of $6 \%$ of total STD claims). 
The qualitative/quantitative study had three components: (1) internal interviews with Unum claims managers, (2) external interviews with companies who experience high and low mental health claims, and (3) a quantitative review of the descriptive statistics associated with the mental health disability claims of 15 companies, totaling157,286 STD claims. Companies were selected based on STD incidence rates using a cross-section of employers who were at, below, and above the mean mental health incidence rate. A member of the health and productivity team conducted internal interviews while a third-party research vendor conducted the external interviews. The intent of the study was to learn and share potential best practices with other companies to improve workplace culture and mitigate mental health disabilities.

The internal and external sets of interview questions were designed to learn about workplace culture that may or may not contribute to mental health disabilities. Questions for companies were concentrated in a few focused categories: (a) benefits and resources available to employees; (b) workplace culture and stigma related to disability and mental illness; (c) work-life balance in the workplace; and (d) people management efficacy. Internal questions focused on gathering information related to effective workplace practices that facilitate return to work and prevent disability situations from occurring. These included (a) what can employers do to encourage return to work for employees out of work on a mental STD claim; (b) what is the most common reason employees indicate they cannot return to work; (c) what is the most common precipitant of the inability to work due to a mental health condition; and (d) name a best practice employers can use to facilitate return to work from a mental health condition.

\section{Participants}

Six companies participated in the study, and all had over 2000 employees. These companies were selected based on their mental health disability experience (defined as annual rates of STD claims and included all ICD-9 categories, provider diagnosis codes, defined as mental health). The study sought three participant companies with high mental health disability experience, defined as greater than $10 \%$ of the overall STD claims. In addition, there were three companies with a less than average mental health disabled population defined as less than $6 \%$ of overall STD claims. All of the participants were voluntary and data were kept confidential. Participating companies varied in terms of industry, including retail, insurance, research and development, and beverage production and distribution. Each organisation was insured for short-term disability and long-term disability through Unum. Also of note, four of the six organisations had call centre operations; call centres have above average mental health disability incidence. Each com- pany offered one or two participants for the interview process and each were members of the HR department. Eight 30 to 60 minute interviews were completed in total, as two companies offered two interviewees.

In addition, there were 20 disability claim managers interviewed in two focus groups (10 per focus group). The claim managers were responsible for disability, managing mental health claims, for the disability insurance provider (Unum). The claim managers were an even mix of men and women with various tenure in the disability field, including one year to 10 years of disability management experience. Each claim manager had been managing only mental health disability claims for one year.

\section{Data Collection}

Internal interviews with disability claim managers were conducted as focus groups. The interviewer met with two teams of claim managers who were responsible for disability, managing companies' mental health claims, which were insured with Unum. There were 10 participants in each focus group and the discussion lasted for one hour. The participants were asked to share thoughts in reaction to interviewer questions (provided earlier). The interviews were conducted in a conference room and the interviewer was able to be present in person in one focus group and on the telephone for the second focus group. All interview responses were documented, analysed and synthesised to find major themes.

A third-party research firm conducted the external interviews of the eight HR personnel. These eight participants were asked to participate in this research, and agreed under the caveat that identity would remain confidential. The research firm interviewer scheduled 60-minute interviews with each of the HR company participants, which were conducted by telephone. The interviews were recorded, transcribed, and analysed for major themes.

\section{Data Analysis}

Both quantitative and qualitative data analysis conducted. The quantitative review of 157,286 covered employees across a continuum of mental health incidence rates was analysed using descriptive statistical review to identify incidence, duration and return-to-work patterns for 2013. The data were analysed across variables including age, gender, job title, ICD-9 category, and industry.

A pragmatic knowledge claim approach was used in the qualitative portion of this study, which is a common mixed methods design (Creswell, 2003). The qualitative analysis for each of the semistructured interviews was transcribed and thematic analysis was selected to identify, analyse, and report patterns and themes within data (Braun \& Clarke, 2006). The company interviews were then aggregated to determine meaningful patterns and 
trends among the group. The groups were separated in two and analysed according to their level of disability experience; high or low. The two groups were dissected to find separate meaningful patterns and trends. The two groups were aggregated in order to look for comprehensive group-level trends. Each group displayed an essence of experience, and the aggregate group also displayed a common theme. Finally, the claim manager focus groups were analysed and compared to the outcomes from the company interviews to determine final consistent trends.

\section{Results}

Based on the quantitative results, individuals aged 40 to 49 had the highest incidence of mental health claims, with women twice as likely to file a mental health claim. Consistent with previous Unum studies, anxiety and depression were the most common reasons for mental health-related absence from work. The 15 companies, with over 2000 employees, in the quantitative portion of the study had differences related to duration of mental health claims. Companies with low incidence tended to have longer durations of claims and the most severe diagnoses experienced the longest durations. Employees both male and female age 50 to 59 experienced the longest time away from work but younger women tended to experience mental health claims lasting for shorter durations. Companies with high mental health claims tended to have large call centre operations, where mental health claims tend to be higher due to high stress, high production, low control jobs, which contribute to risk of higher job dissatisfaction (Cuijipepers et al., 2012).

An emerging theme related to this study was that supportive environments may actually lead to higher mental health STD claims. Based on qualitative interviews of claims managers and HR personnel (from companies in the study), companies with a strong corporate culture, work-life balance, good benefits and successful wellness programs appear to create a work environment where many leaves of absences are supported and accepted. The higher rates of mental health STD overall in these companies reflects employer support of mental health claims and employee comfort in disclosing and seeking help. Conversely, companies who were undergoing restructuring or were impacted by industryrelated cycles were characterised as having lower morale, minimal employee-perceived support of work-life balance and wellness, yet had lower rates of mental health STD leave. This current study did not look at the impact on other aspects of these companies (higher long-term disability or workers compensation rates, issues with presenteeism, high turnover, etc.).

The study also found some consistencies among the high and low mental health claims incidence groups. Results of HR personnel high and low incidence groups found issues related to management style. In each category of organisation managers were noted to be technical experts and lacking in people management skills. One employer noted, 'we know employees don't leave their company they leave their leader and that is an opportunity for improvement for us'. For the low mental health claim utilisation group, managers perpetuated stigma and failed to recognise high stress and low control environment. Another employer said, 'the pressure is high and managers feel like the light (signifying you are working) should be on or clearly you don't have enough to do'. On the high mental health claim incidence side, the environment was noted to be more supportive of the need for disability, but managers were also said to avoid performance discussions and suggest disability as a means of coping with performance issues and stress related issues. One company noted 'managers really don't know how to handle mental health, it can be difficult to know how to talk to someone when they have initial difficulty as well as when they return to work'.

While this was a preliminary study, information received points to some conclusions. Lower rates of mental health STD claims are possibly tied to the perception of job security as those employees in less supportive cultures may feel stigma and even potential of job loss by going out on mental health STD. Furthermore, there are issues with return to work for mental health claims as issues with re-joining the workplace that may be due to work-based anxiety. Unum mental health claims managers found that a significant contributor to absence from work, related to mental health diagnoses, was due to the work environment, and a significant barrier to return to work was also the work environment. Thus, it appears that older workers or the age group of 50 to 59 experience more severe symptoms and anxiety related to return to work. The claim manager focus groups revealed that this population may feel more anxiety about the ability to perform at the predisability level, and is also more sensitive to mental health stigma that may contribute to longer durations away from work.

\section{Discussion}

Further research is needed to explore the impact on other leave programs, such as long-term disability, workers compensation and health care utilisation rates, with employers who had a strong supportive culture and a higher rate of mental health STD claims. Research needs to be conducted to determine how employers are impacted in other leave programs, and determine presenteeism and health care costs overall for employers with supportive cultures. Seeking help for mental health conditions, which are often treatable and employees can return to work productively, may in fact save employers money in the long run instead of employees remaining at work when time off is warranted for treatment. Findings from this study regarding higher rates of STD 
mental health claims in supportive employer cultures should not be seen as a negative and deter employers from creating supportive work environments because there is a perception that STD mental health claims will increase.

Additional research around costs associated with negative workplace culture, and the impact on the mental health of employees is needed. The cost of mental health has been documented, yet additional research needs to be conducted around poor employer culture and costs, specifically in regard to employees who do not feel supported to take mental health leave when needed due to stigma, fear of disclosure and/or poor employer supports. Best practices for the development and implementation of return-to-work programs for employees with mental health conditions are also merited to ensure successful employment once a leave of absence is complete.

Outcomes from this study reflect previous research findings in multiple areas including higher mental health STD claims for employees working in call centres, and the highest incidence rates of mental health claims in those aged 40 to 45 (40-49 in current study). Prevalence of depression and anxiety was also reflected in this study, and consistent with previous research, with those two conditions identified as most common reasons for mental health STD claims.

\section{Limitations}

Concerns regarding ongoing management and performance issues that may prove to influence mental health STD claims, as well as create return-to-work barriers, may have an impact on results. Further study is needed in this area to determine how stress due to performance may contribute to mental health STD claims as well as general stress in the workplace overall. Additional information regarding employee perception of workplace culture and reasons for filing mental health STD claims was not identified in this study. Further study incorporating employee perceptions of workplace culture as an aspect of mental health disclosure is critical.

\section{Best Practices}

As discussed earlier, as the workforce ages there is a higher proportion of employment discrimination charges being filed, and mental health disabilities are the most recurrent health condition cited. To proactively address this trend, employers have an increasing incentive to implement policies and programs that are responsive to the needs of these workers, both to minimise possible legal issues, such as EEOC discrimination charges (Bjelland et al., 2010), and to maximise employee productivity (Habeck, Leahy, Hunt, Chan, \& Welch, 1991). A study in 2013 that surveyed disability management professionals found that over $85 \%$ of employer respondents reported that their organisation was

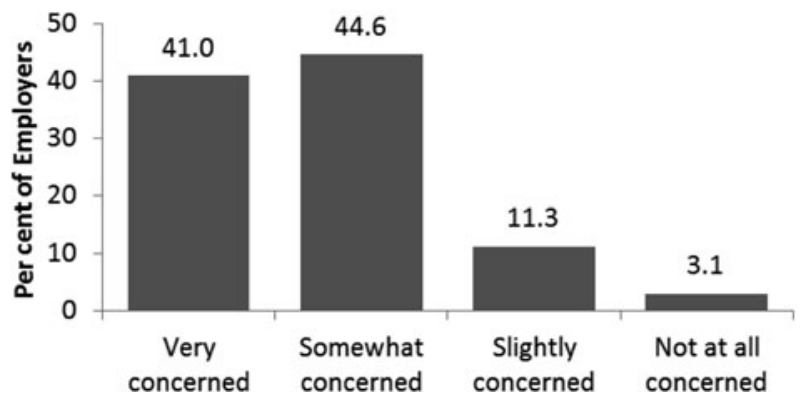

\section{FIGURE 1}

Organisational concern about the impact of an aging workforce. Source: von Schrader, Bruyère, Malzer and Erickson, 2013.

either 'very' or 'somewhat' concerned about the impact of an aging workforce on their organisation (von Schrader, Bruyère, Malzer \& Erickson, 2013).

In response to these concerns, some employers have taken aging into account in the design of their disability management programs. In particular, these employers have identified several specific 'leading practices' in adapting programs for an aging workforce. It is important to note that while these practices are identified as benefiting aging workers specifically, they can have a positive impact on the entire workforce, and create a positive work environment leading to better mental health of all employees. In particular, employers in the 2013 study of disability management professionals highlighted the following as important (von Schrader et al., 2013):

- Flexibility, including flexible scheduling, part time/seasonal scheduling, flex-place opportunities, and flexible leave policies.

- Maintaining and enhancing benefits, including providing benefits education programs, bridging or enhancing benefits for individuals easing into retirement, and providing short and long term disability policies.

- Wellness programming, including preventive health programming, disease management programs, onsite wellness programming, integrating wellness programs with health insurance, incentives for participating in wellness activities, work-life resources, Employee Assistance Programs, and comprehensive health initiatives. Employers also noted the importance of using employee data to assist in selecting targeted wellness interventions to those issues that are most costly to the organisation or most prevalent among employees (e.g., tobacco use, obesity, etc.).

- Safety checks, including ensuring appropriate use of equipment and technology and "creating a culture of safety'.

- Accommodations, including being creative in providing accommodations, building strategies and support systems, reaching out to local and regional resources 
for support in providing accommodations, and updating job descriptions to ensure they are accurate and properly identify essential functions.

- Stay-at-work and return-to-work programs that include personalised case management, programs that support staying at work or transitioning back to work after an absence, work training and career progression programs, and mentoring to support employees into moving into new roles.

- Communication and culture programs that focus on equipping managers to deal with disability, aging and absence, including helping support managers in having conversations with their employees.

In a study by Cornell University to determine the extent to which companies were employing good practices in the accommodation and retention of individuals with disabilities, a survey was conducted of approximately $600 \mathrm{HR}$ professionals who were members of the Society for Human Resource Management (Erickson, von Schrader, Bruyère, \& VanLooy, 2013). Results showed that nearly three quarters of respondents reported a designated office or person to address accommodation issues. About two-thirds had a grievance procedure and allowed employees to exceed the maximum medical leave duration as an accommodation, and less than half (44\%) had a formal decision-making process for accommodations. In terms of retention practices, three-quarters had a return-to-work or disability management program, and slightly over half encouraged flexible work arrangements for all employees (e.g., flextime, part-time, telecommuting; Erickson et al., 2013). These recommendations are directly in line with those identified earlier in this article as promoting accommodation and retention of employees with mental health/behaviorial disabilities. If employers are serious both about retaining workers as they age and keeping them productively in the workplace, many more employers will be needing to use more of these practices with further regularity.

\section{Conclusion}

The workplace environment contributes to both the treatment of employees with disabilities, and the overall health of employees, by creating or aggravating disability, especially in the area of mental health. Knowing the current and imminent impact mental health has on employers, research determining workplace factors that either alleviates, or contributes to mental health, needs to be conducted. As the workforce ages these issues will continue to be present and 'employers thus have a vested economic and social interest in the mental health condition of their workers and would benefit from developing and instituting programs and policies within the workplace designed to detect, intervene with, and accommodate individuals with mental health disabili- ties' (Gallie et al., p. 296). Workplace productivity is tied to employers who facilitate investing in employee health, wellbeing and the quality of work-life balance (Lerner et al., 2011).

\section{Acknowledgements}

The authors would like to acknowledge Cornell University, and the following colleagues whose research is also reflected in this article: William Erickson, Sarah von Schrader, and Sara VanLooy.

\section{References}

Alwan, A. (2011). Global status report on noncommunicable diseases 2010. Geneva, Switzerland: World Health Organization.

Arnetz, B., Lucas, T., \& Arnetz, J. E. (2011). Organizational climate, occupational stress, and employee mental health: Mediating effects of organizational efficiency. Journal of Occupational and Environmental Medicine, 53(1), 34-42. doi:10.1097/JOM.0b013e3181ffo5b

Baldwin, M., \& Marcus, S. (2011). Stigma, discrimination, and employment outcomes among persons with mental health disabilities. In I. Schultz \& S. Rogers (Eds.), Work accommodation and retention in mental health (pp. 53-69). New York, NY: Springer. doi:10.1007/978-1-4419-0428-7_3

Bjelland, M. J., Bruyère, S. M., von Schrader, S., Houtenville, A. J., Ruiz-Quintanilla, A., \& Webber, D. A. (2010). Age and disability employment discrimination: Occupational rehabilitation implications. Journal of Occupational Rehabilitation, 20(4), 456-471. doi:10.1007/s10926-009-9194-z

Braun, V., \& Clark, V. (2006). Using thematic analysis in psychology. Qualitative Research in Psychology, 3(2), 77-101. doi:10.1191/1478088706qp063oa

Briand, C., Durand, M., St-Arnaud, L., \& Corbière, M. (2007). Work and mental health: Learning from return-to-work rehabilitation programs designed for workers with musculoskeletal disorders. International Journal of Law and Psychiatry, 30, 444-457. doi:10.1016/j.ijlp.2007.06.014

Bronkhorst, B., Tummers, L., Steijn, B., \& Vijverberg, D. (2014). Organizational climate and employee mental health outcomes: A systematic review of studies in health care organizations. Health Care Management, 39, 1-18. doi:10.1097/HMR.0000000000000026

Center, C. (2011). Law and job accommodation in mental health disability. In I. Z. Schultz \& E. S. Rogers (Eds.), Work accommodation and retention in mental health (pp. 3-32). New York, NY: Springer Science and Business Media.

Claxton, A., Chawla, A., \& Kennedy, S. (1999). Absenteeism among employees treated for depression. Journal of Occupational and Environmental Medicine, 41(7), 605-611. doi:10.1097/00043764-199907000-00009

Creswell, J. W. (2003). Research design: Qualitative, quantitative, and mixed methods approaches (2nd ed). Thousand Oakes, CA: Sage.

Cuijipers, P., Beekman, A. T. F., \& Reynolds, C. F. (2012). Preventing depression: A global priority. Journal of the American Medical Association, 307(10), 1033-1034. doi:10.1001/jama.2012.271

Dalgin, R. S., \& Bellini, J. (2008). Invisible Disability Disclosure in an Employment Interview: Impact on Employers' Hiring Decisions and Views of Employability. Rehabilitation Counseling Bulletin, 52(1), 6-15.

Dalgin, R. S., \& Gilbride, D. (2003). Perspectives of people with psychiatric disabilities on employment disclosure. Psychiatric Rehabilitation Journal, 26(3), 306-310. 
Dewa, C., Lin, E., Kooehoorn, M., \& Goldner, E. (2007). Association of chronic work stress, psychiatric disorders, and chronic physical conditions with disability among employees. Psychiatric Services, 58(5), 652-658.

Dewa, C., \& McDaid, D. (2011). Investing in the mental health of the labor force: Epidemiological and economic impact of mental health disabilities in the workplace. In I. Schultz \& S. Rogers (Eds.), Work accommodation and retention in mental health (pp. 33-51). New York, NY: Springer. doi:10.1007/978-1-4419-0428-7_2

Disability Case Study Research Consortium. (2008). Conducting and benchmarking inclusive employment policies, practices, and culture. Washington, DC. Author.

Eriksen, W., Tambs, K., \& Knardahl, S. (2006). Work factors and psychological distress in nurses' aides: a prospective cohort study. BMC Public Health, 6, 290. doi:10.1186/1471-2458-6290

Erickson, W. A., von Schrader, S., Bruyère, S. M., \& VanLooy, S. A. (2013). The employment environment: Employer perspectives, policies, and practices regarding the employment of persons with disabilities. Rehabilitation Counseling Bulletin, 57(4), 195208. doi:10.1177/0034355213509841

Faragher, E., Cass, M., \& Cooper, C. (2005). The relationship between job satisfaction and health: A metaanalysis. Occupational Environmental Medicine, 62(2), 105-112. doi:10.1136/oem.2002.006734

Ferrari, A. J., Charlson, F. J., Norman, R. E., Patten, S. B., Freedman, G., Murray, C. J., ... \& Whiteford, H. A. (2013). Burden of depressive disorders by country, sex, age, and year: Findings from the global burden of disease study 2010. doi: 10.1371/journal.pmed.1001547

Godin, I., Kornitzer, M., Clumeck, N., Linkowski, P., Valente, F., \& Kittel, F. (2009). Gender specificity in the prediction of clinically diagnosed depression. Results of a large cohort of Belgian workers. Social Psychiatry and Psychiatric Epidemiology. 44(7), 592-600. doi:10.1007/s00127-008-0465-3

Gallie, K., Schultz, I., \& Winter, A. (2011). Company-level interventions in mental health. In I. Schultz \& S. Rogers (Eds.), Work accommodation and retention in mental health (pp. 295309). New York, NY: Springer. doi:10.1007/978-1-4419-04287_15

Gnam, W. (2005). The prediction of occupational disability related to depressive and anxiety disorders. In I. Schultz \& R. Gatchel (Eds.) Handbook of complex occupational disability claims. Early risk identification, intervention and prevention (371-386.). New York, NY: Springer. doi:10.1007/0-387-28919-4_20

Juniper, B. (2012). Price of presenteeism. Occupational Health, 64(5), 26.

Habeck, R.V., Leahy, M.J., Hunt, H.A., Chan, F., \& Welch, E.M. (1991). Employer factors related to workers' compensation claims and disability management. Rehabilitation Counseling Bulletin, 34(3), 210-226.

HR Specialist. (2013). Compensation \& Benefits. 10 ways to reduce the threat of 'presenteeism'. Retrieved from http://www.businessmanagementdaily.com/34124/10-waysto-reduce-the-threat-of-presenteeism

Kelloway, E.K., \& Day, A.L. (2005). Building healthy workplaces: What we know so far. Canadian Journal of Behavioral Science, 37(4), 223-235. doi:10.1037/h0087259

Kessler, R.C., Berglund, P., Demler, O., Jin, R., Merikangas, K.R., \& Walters, E.E. (2005). Lifetime prevalence and age-of-onset distributions of DSM-IV disorders in the National Comorbidity survey replication. Archives of General Psychiatry, 62(6), 593-602. doi:10.1001/archpsyc.62.6.593
Keyes, C. (2005). Chronic physical conditions and aging: Is mental health a potential protective factor? Ageing International, 30(1), 88-104. doi:10.1007/BF02681008

Lerner, D., Adler, D., Hermann, R., Rogers, W., Chang, H., Thomas, P., ... Perch, K. (2011). Depression and work performance: The work and health initiative study. In I. Schultz \& S. Rogers (Eds.), Work accommodation and retention in mental health (pp. 103-120). New York, NY: Springer. doi:10.1007/978-1-4419-0428-7_6

MacDonald-Wilson L., K. (2005). Managing disclosure of psychiatric disabilities to employers. Journal of Applied Rehabilitation Counseling, 36(4), 11.

Madaus, J. W. (2008). Employment self-disclosure rates and rationales of university graduates with learning disabilities. Journal of Learning Disabilities, 41(4), 291-299. doi: 10.1177/0022219407313805

Martin, A., Karanika-Murray, M., Biron, C., \& Sanderson, K. (2014). The psychosocial work environment, employee mental health and organizational interventions: Improving research and practice by taking a multilevel approach. Stress and Health. Online ahead of print. doi:10.1002/smi.2593

McCulloch, J., Ozminowksi, R., Cuffel, B., Dunn, R., Goldman, W., Kelleher, D., \& Comporatos, A. (2001). Analysis of a managed psychiatric disability program. Journal of Occupational and Environmental Medicine, 43(2), 101-109. doi:10.1097/00043764-200102000-00006

Moss, K., Ullman, M., Starrett, B. E., Burris, S., \& Johnsen, M. C. (1999). Outcomes of employment discrimination charges filed under the Americans with Disabilities Act. Psychiatric Services, 50(8), 1028-1035. doi:10.1176/ps.50.8.1028

Nishii, L., \& Bruyère, S. (2014). Research brief: Inside the workplace: Case studies of factors influencing engagement of people with disabilities. Ithaca, NY: Employment and Disability Institute. http:// digitalcommons.ilr.cornell.edu/edicollect/1351/

Society for Human Resource Management. (2009). 2009 Employee Benefits (White Paper). Alexandria, VA: Author. Retrieved from www.shrm.org

Stewart, W. F., Ricci, J. A., Chee, E., Hahn, S. R., Morganstein, D. (2003). Cost of lost productive work time among U.S. workers with depression. Journal of the American Medical Association, 289, $3135-3144$.

Toossi, M. (2007). Employment outlook: 2006-2016: Labor force projections to 2016: More workers in their golden years. Monthly Labor Review, 130(11), 33-52.

von Schrader, S. (2011). Calculations from EEOC Charge Files. Ithaca, NY: Cornell University Employment and Disability Institute.

von Schrader, S., Bruyère, S., Malzer, V., \& W. Erickson. (2013). Absence and disability management practices for an aging workforce. Ithaca, NY: Cornell University Employment and Disability Institute. Available at http://digitalcommons.ilr.cornell.edu/cgi/ viewcontent. cgi?article $=1320 \&$ context $=$ edicollect

von Schrader, S., Malzer, V., Erickson, W., \& Bruyère, S. (2011). Emerging employment issues for people with disabilities. Ithaca, NY: Cornell University. Available at http://digitalcommons.ilr.cornell.edu/cgi/viewcontent.cgi? article $=1288 \&$ context $=$ edicollect

Watson Wyatt Worldwide. (1998). Staying at work survey, 1998. Alexandria, VA: Author. Retrieved from www.watsonwyatt. $\mathrm{com} /$ publications.

Watson Wyatt Worldwide. (2000) Staying at work 2000/2001the dollars and sense of effective disability management. Vancouver, Canada: Author.

World Health Organization. (2005). Mental health policies and programmes in the workplace. Geneva, Switzerland: Author. 